\title{
Total knee arthoplasty: better short-term results after subvastus approach
}

\author{
Gayle Maffulli $\cdot$ Stephen Bridgman • \\ Nicola Maffulli
}

Received: 15 December 2009/Accepted: 8 November 2010/Published online: 11 December 2010

(C) Springer-Verlag 2010

\section{Dear Editors,}

We have read with great interest and appreciation the article entitled "Total knee arthoplasty: better short-term results after subvastus approach: a randomized, controlled study." [2]. We congratulate the authors for the work performed and for trying to inject some science in the issue of which approach is more effective in total knee arthroplasty.

We wish to bring to the attention of the authors the article "Sub-vastus approach is more effective than a medical parapatellar approach in primary total knee arthroplasty: a randomized controlled trial" [1]. We are surprised that the authors do not reference the above investigation. We do recognise that between the time of acceptance for publication (19th June 2008) and actual publication (3rd March 2009) there is a significant time lag. The above article was published on 9th January 2009.

Our study was also a controlled double-blind randomised trial with 231 patients recruited and completing the study: more than twice the number in the Sergi et al. study [2]. We call attention to the readership that, in our study, we employed the Knee Society Score, a specific assessment tool for knee function. In the Results section, Sergi et al. [2] indicate that " 104 patients were distributed in two groups: the SV group with 56 patients and the PP group

G. Maffulli · N. Maffulli ( $\square)$

Centre for Sports and Exercise Medicine, Queen Mary

University of London, Barts and The London School

of Medicine and Dentistry, Institute of Health Sciences

Education, Mile End Hospital, 275 Bancroft Road,

London E1 4DG, UK

e-mail: n.maffulli@qmul.ac.uk

\section{S. Bridgman}

Department of Public Health, Guernsey, Channel Islands with 48 patients." Later, the text reports that "The final number of patients that had complete follow-up data was 100,52 in the PP group and 48 in the SV."

We wonder how there could be 52 patients in the parapatellar group when there were only 48 patients to start with. This questions whether appropriate group allocation analysis was followed.

In the Discussion section, Sastre et al. [2] comment that they found no difference at 12 months between the two groups. Our own study [1] found that, at same follow-up point, the WOMAC global and pain scores, SF36 physical function and role-physical scores and EuroQol utility and pain score were all significantly in favour of the subvastus approach. We stress that, when performing randomised controlled trials, not only the study should have enough statistical power, but outcome measures specific for the condition and anatomical district studied should be used.

\section{References}

1. Bridgman SA, Walley G, MacKenzie G, Clement D, Griffiths D, Maffulli N (2009) Sub-vastus approach is more effective than a medial parapatellar approach in primary total knee arthroplasty: a randomized controlled trial. Knee 16:216-222

2. Sastre S, Sanchez MD, Lozano L, Orient F, Fontg F, Nuñez M (2009) Total knee arthroplasty: better short-term results after subvastus approach: a randomized, controlled study. Knee Surg Sports Traumatol Arthrosc 17:1184-1188 